compared to $22 \%(9 / 41)$ of offspring of nonschizophrenic parents. Poor psychiatric adjustment at adolescence was preceeded by problems at an earlier age. (Hans SL, Marcus J, Nuechterlein KH et al. Neurobehavioral deficits at adolescence in children at risk for schizophrenia. Arch Gen Psychiatry August 1999;56:741-748). (Reprints: Sydney L Hans PhD, Department of Psychiatry, MC3077, The University of Chicago, 5841 S Maryland Ave, Chicago, IL 60637).

COMMENT. Neurobehavioral signs in infants, children and adolescents may be markers of vulnerability to schizophrenia and poor global psychiatric adjustment. Risk factors for development of schizophrenia in offspring of schizophrenics include motor and sensorimotor behavior problems during the first year of life and poor motor and cognitive functioning during school age. Male offspring are more susceptible than girls.

Chromosome anomaly in autism and epilepsy. A 12-year-old boy with atypical autism and epilepsy had a maternally derived duplication of chromosome 15q11-q13. (Gurrieri F et al. Neurology May 1999;52:1694-1697).

\title{
ADHD CLINICAL FINDINGS IN FEMALES
}

Clinical correlates of attention deficit hyperactivity disorder in females were examined in 140 girls with ADHD and compared with 122 girls without ADHD in a study at the Massachusetts General Hospital, Boston. Compared to controls, girls with ADHD manifested more conduct, mood, and anxiety disorders, lower IQ and achievement scores, and more impairment on measures of social, school, and family functioning. Comorbidity findings and severity of intellectual impairments are similar to those in boys with ADHD. (Biederman J, Faraone SV, Mick E et al. Clinical correlates of ADHD in females: findings from a large group of girls ascertained from pediatric and psychiatric referral sources. IAm Acad Child Adolesc Psychiatry August 1999;38:966-975). (Reprints: Dr Biederman, Pediatric Psychopharmacolgy Unit, ACC 725, Massachusetts General Hospital, Fruit St, Boston, MA 02114 ).

COMMENT. With the exception of low levels of disruptive behavior, ADHD in girls has a spectrum of symptoms and comorbidity, with mood and anxiety disorders, and impairments in cognitive functioning, school achievement, social and family functioning, similar to those found in boys.

\section{LANGUAGE-RELATED DEFICITS AFTER TEMPORAL LOBECTOMY}

Five left temporal lobectomy school-aged children demonstrated significant language-related cognitive declines on post-operative neuropsychological testing at the Children's Hospital of Philadelphia, PA. Deficits involved verbal IQ verbal learning, naming, and reading comprehension. They were clinically evident in 4 of the 5 patients, leading to impaired school performance. They were not identified by IQ testing alone. Three right temporal lobectomy patients showed no cognitive impairment after surgery. (Dlugos DJ, Moss EM, Duhaime A-C, Brooks-Kayal AR. Language-related cognitive declines after left temporal lobectomy in children. Pediatr Neurol July 199;21:444-449). (Respond: Dr Dennis J Dlugos, Division of Neurology, 6th Floor, Wood Bldg, Children's Hospital of Philadelphia, Philadelphia, PA 19104).

COMMENT. Preoperative and postoperative neuropsychological testing is recommended in children undergoing temporal lobectomy for epilepsy. Left temporal lobectomy may be complicated by language-related cognitive declines. 